\title{
THE RUMORED EXISTENCE OF OTHER PEOPLE
}

I dreamt my household consisted largely of objects manufactured by people I would never meet or know and some of these objects dangled down from the ceiling while others towered dizzily upwards from the floor.

If most of them stayed where I left them as if dozing in embryonic thought, still others came with features conducive to movement, making them appear more endearingly alive as they powered up and off in search

of excitement, an hour's diversion-no harm in that. Intuition stopped short of determining whether or not any of the objects kept in contact with their makers via some kind of bond, perhaps a physical connection

explicable through science, or else a spiritual affinity notoriously difficult for an outside party to understand. But the more I gave it thought the more it seemed to me believable. A silver line, a souvenir, a sieve of relation

meaning to release something lovingly means always remaining tied to it. As to be somewhere completely means never having to leave. I thought to figure out how many presences collected around me at that moment.

Did they possess consciousness, would they cooperate. Should I expect a new kind or the mundane damages. Everywhere I might be now in light of where I've been. I dreamt I held out my hand and before long a banana 
flew up from the industrious parenthesis of Costa Rica and provided for that hand before it knew it wanted. Start slow, be consistent, and your levels will increase. I dreamt the will of manufacturers to produce goods

was shed from those goods long after they were made. All the windows overlooking a landfill or production site. The more I gave it thought the more it seemed to me obvious. Also touching. Whoever built that warehouse

across the way built it thinking someone would one day look at it in wonder. Also sorrow. To keep an endless store of that feeling. To make, to provide it. That I might turn my back on a building like that will have become unthinkable tomorrow, when my sympathy with most abandoned things is effectively cut from the budget. I dreamt in increments of three, five, and eventually ten. Not the way the objects at hand rubbed me but more the way those beyond me made me pang for them there. I might even say the walls, the floors, the plush carpets unrolled on the floors and the furniture, the refrigerator and any item in it, nautical tchotchkes and the curtains

clamped tight as August quahogs to optimize my output. The shedding of the will, too, takes place incrementally across decades, late at night, the little shifting in a room's air profile comparable to a ghost's entrance if not quite

equivalent. At work beyond the warehouse, everything else: droplets on navy felt, protection sensed in a system whose products had begun to forecast accurate wants. I dreamt a body's indentation beside me on the mattress 
vanishing as the presence found the door through a film adaptation of silence. Child with gifts for ravens in pockets. Lady affianced to alien abduction. Figure of the human experiment almost over. I open my mouth and in no time

lasagna, Chianti, a greater than expected rate of melting, atrophy, military action, and a ravenousness that shook my confidence and the hinged box I keep pin money in. The rumble of it recalls the convulsion Plato says the gods

sank Atlantis with to chasten its inhabitants, whose vast majority descended from Poseidon and one of the island's earth-born shepherdesses. As long as divinity remained predominant in their nature, Atlanteans kept obedient to

the laws of their progenitor, but over time, what was divine diminished, and love of wisdom and virtue gave way to love of wealth and luxury, which in the past had seemed merely distractions. To those who lacked the ability to see

through the radiance of things, the Atlanteans appeared to be thriving: palaces, baths, mines rich in orichalcum. Herds of elephants. Vineyards, orchards. Access to upwards of a dozen sherbets. The chance to astonish houseguests

with golden oblongs and lozenges. To watch as vampires turned mortals into vampires for cash, despite the fact that vampires could easily devise a life without having to dirty their pale hands with money again, but apparently

nothing restores that old vitality like a night of spending. I dreamt a percentage of my money had been touched by entrepreneurs of the undead. I dreamt I'd never guess how much. Dreamt no idea where my money had been. 
What bathroom floor or choir stall or Alp or what disgrace. Dreamt I couldn't taste a difference. Dreamt my money might want company, and I had better not keep putting it in my mouth in that case. As drawing from a songbird's

coloratura, I dreamt the secret to prosperity is being commonesque. Profiteroles, remote control, the ruin of my body. And tremulous as horses hidden in old plaster. Confused as vinyl siding. Certain as what's happening

can't have all at once, or even all that fast, but by degrees imperceptible until too late, eyes trained to other tasks as the sheep took to clover, distracted as a vortex of plastic debris measuring twice the size of Texas patched itself

together mid-Pacific, a swirl like a god's intoxicated eye 25 but not surveillant, voyeuristic, a bright new continent only in it for the kicks, its culture to bask, its historiography accidental, with every bit of flotsam serving as a double

record of one product's manufacture and consumption. I dreamt in complex packaging that posed no less a threat at the factory warehouse than up among my cupboards or dropped in the superabundant trash bins at airports.

Found it simple and good to forget that threat by letting perception of such objects eclipse true knowledge of them. Any worry washed in umbra. Like being in the moment only endlessly. I hear the naked hands of strangers make

my dumplings but experience insists what makes them mine is money. I open the door and I extend good money into ancient night, night prosperous with stars, order heavy in my hand. I'm immortal that way. I lie down and I feed. 